\title{
Prediction of ZnO Surge Arrester Degradation Based on Temperature and Leakage Current Properties
}

\author{
Novizon $^{1 *}$, Zulkurnain Abdul-Malek ${ }^{2 *}$, Aulia ${ }^{1}$, Eka Putra Waldi ${ }^{1}$, \\ Abdul Rajab ${ }^{1}$,and Darwison ${ }^{1}$ \\ ${ }^{1}$ Jurusan Teknik Elektro, Fakultas Teknik, Universitas Andalas \\ ${ }^{2}$ Institute of High Voltage \& High Current, Universiti Teknologi Malaysia (UTM), Malaysia \\ *Corresponding author, e-mail: novizon@gmail.com, zulk@fke.utm.my
}

\begin{abstract}
Temperature and leakage current on the $\mathrm{ZnO}$ arrester are interrelated with each other. In low conduction region, voltage-current characteristics of $\mathrm{ZnO}$ surge arrester are highly dependent on temperature. The leakage current will increase as the temperature increases and experience thermal runaway when the temperature exceeds the acceptable limit. This phenomenon is associated with the increase of resistive leakage current due to degradation. Therefore the temperature and leakage current are good indicator to evaluate the condition of $\mathrm{ZnO}$ arrester. This paper proposed the degradation prediction of $\mathrm{ZnO}$ surge arrester by analyzed the temperature and leakage current. The $132 \mathrm{kV}$ station type $\mathrm{ZnO}$ surge arrester was employed. Temperature profile of $\mathrm{ZnO}$ arrester was obtained using thermal camera. The leakage current was measured simultaneous with the temperature measurement to attain the leakage current at the actual temperature. The results shows the leakage current continue increasing by increasing the temperature.
\end{abstract}

Keywords : Resistive leakage current, temperature, degradation, prediction, zinc oxide surge arrester

\section{Introduction}

Surge arrester covers a wide range of power system is of importance in utility protection against surge or switching over voltage. Therefore, the occurring faults in surge arrester may severely affect the continuity of electric supply to industries and consumers.

In order to minimize the numbers of breakdown and to increase the reliability, surge arrester condition should be monitored for indications and initial fault detection. By this, the life of surge arrester could be elongated and the catastrophic consequences of failure could be avoided. Consequently, fault diagnosis and condition monitoring of surge arrester have been a research subject in recent years.

Traditionally, to monitor the conditions and diagnose the surge arrester faults, leakage current and third harmonic of leakage current are commonly used due to their good indicator of degradation of surge arrester. Some outstanding researchers [1-5] have successfully employed these leakage current signal for fault detection and diagnosis areas. However, it is necessary to increase the fault diagnosis capability and implement suitable features which intensify the fault detection ability for $\mathrm{ZnO}$ arrester.

In this research, in order to get accurate condition of arrester the leakage current and temperature were observed simultaneous. The temperature distributionappearing on the $\mathrm{ZnO}$ arrester blocks was observed using thermography camera.

In particular, the correlation betweenthe temperature and leakage current of a $\mathrm{ZnO}$ arrester was analyzed experimentally. From this analysis, the temperature behaviour and phenomenaresulting from the heat generation and dissipation of the $\mathrm{ZnO}$ arrester was discussed.

\section{Thermal Runaway}

When a distribution $\mathrm{ZnO}$ arrester is connected with the electricpower system during normal condition, the DC leakage current flowing throughthe distribution $\mathrm{ZnO}$ arrester is less than 1 $\mathrm{mA}$. However, thetemperature of the $\mathrm{ZnO}$ arrester block increases and the resistancedecreases when the huge surge energy absorption occurs. As a result,the leakage current goes up and the level of heat generation inthe $\mathrm{ZnO}$ arrester block increases sharply. Fig.1 shows the thermalchange curve of 
the $\mathrm{ZnO}$ arrester block. In Fig.1, in the regionbelow the temperature limit, $\mathrm{t}_{1}$, the level of heat generation ofthe $\mathrm{ZnO}$ arrester is lower than the level of heat dissipation.

The temperature decreases gradually, finally reaching a stable conditionas shown in curve B. On the contrary, when the temperatureof the $\mathrm{ZnO}$ arrester block reaches a level of higher than the temperaturelimit $t_{2}$, the level of heat generation becomes higher than the level of heat dissipation and degradation occurs as shown by curve $\mathrm{A}$ at the end, ultimately resulting in thermal runaway [6].

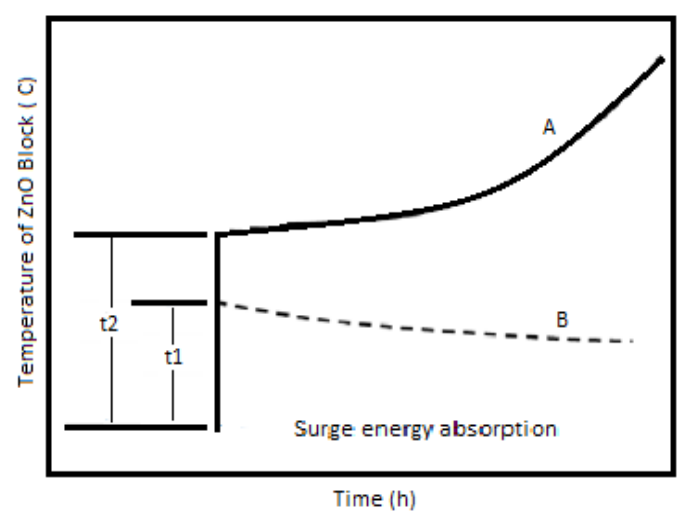

Figure 1. Thermal runaway phenomenon [6].

\section{Thermal Stability}

Thermal stability is one of the important application criteria for $\mathrm{ZnO}$ arresters. The thermal model is analysed with the help of heat loss-input diagram given by M.V. Lat shown in Fig. 2. The dash line at figure 2 represents the power dissipation of arrester element at constant applied voltage $(50 \mathrm{~Hz})$. The solid line represents the ability of the $\mathrm{ZnO}$ element to dispose heat to the atmosphere which is proportional to the temperature above the ambient temperature.

Accordingly, the two curves has an intersection at two points: one at low temperature called as stable operating point and other at high temperature called as instability threshold point. To achieve the thermal stability, the power dissipation in the element should be balanced against the heat lost to the environment. Regions I and III in the Fig. 2 shows instability condition, where if the power dissipation exceeds heat lost from the element. Due to this phenomenon, the energy will be stored in the arrester element and leads to an increase in temperature. Region II is where heat loss exceeds the powerdissipation in the element. Therefore, the temperature of the element always settles at the stable operating point between regions I and II till the temperature value does not exceed instability threshold point. If there is an increase in the temperature then there will be an divergence beyond the instability threshold point will leads to the thermal runaway.

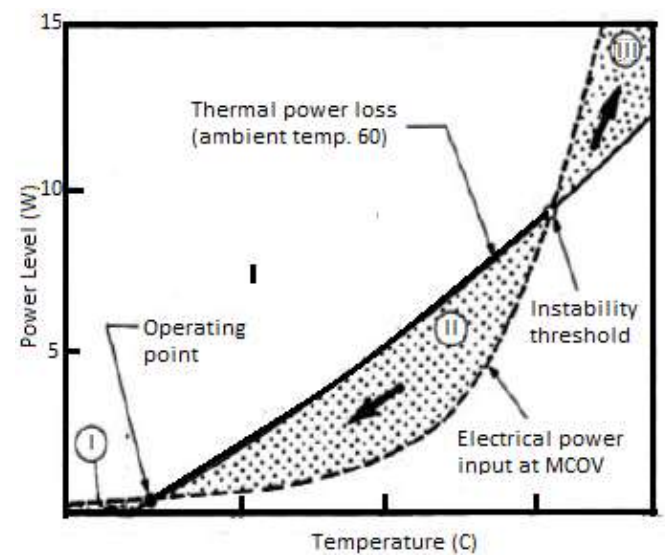

Figure 2. Thermal stability profile [3]

\section{Leakage Current and Temperature}

The measurement of total leakage current flowing through $\mathrm{ZnO}$ surge arrester under normal conditions is used as one of the health monitoring techniques. However, the total leakage current measurement does not indicate the severity of degradation of $\mathrm{ZnO}$ element as the resistive current $\left(\mathrm{I}_{\mathrm{r}}\right)$ is only $15-25 \%$ of the total leakage current $[2,7,8]$. Hence, a sharp increase in resistive current due to degradation or ageing of $\mathrm{ZnO}$ blocks does not affect the total leakage current considerably. The higher resistive leakage current may ultimately bring in the $\mathrm{ZnO}$ surge arrester to thermal instability and may result in a complete failure or breakdown of the arrester. The third harmonic of the resistive leakage current is the true indicator of health of $\mathrm{ZnO}$ surge arrester in service.

Many researchers conducted researches to separate the resistive leakage current from the total leakage current [9]. The shifted current method claims that it can be separate the resistive leakage current with 95\% accuracy [10]. The method based on waveform manipulation to get capacitive current of leakage current and subtracted it to get the resistive part of the leakage current. 
The resistive component of the leakage current is responsible for the heating of the surge arrester (in the absence of external factors) and its increase is reflected as an increase in the temperature of the equipment. If the surge arrester is in perfect condition, such heating is practically uniform on the surface and will be within predetermined limits. On the other hand, the occurrence of degradation may change the distribution of currents in the arrester blocks.

When this occurs, the $\mathrm{ZnO}$ grains could be allowing the passage of an amount of current higher or lower than normal. In the first case, the grain behaves like a short circuit, increasing the current passing through it and, consequently, decreasing the current in its vicinity.

The degradation generates the appearance of hot spots or hot regions. The leakage current and temperature therefore display a relationship of complimentarily and can be combined to use as indicator of arrester condition.

\section{Research Metodology}

Device under test is a used $132 \mathrm{kV}$ station type gapless surge arrester. The experimental carried out in the laboratory and diagram of experimental arrangement of leakage current measurement are as shown in Fig. 3. The configuration consisted of an adjustable voltage source, a voltage regulator, a step up transformer, a protective resistor and test object (surge arrester) in series with shunt resistor. The surge arrester was placed on the platform of the measurement system. A portable thermography camera was used to capture temperature of metal surge arrester through the thermography image, and at the same time the leakage current was also measured through the shunt resistor and recorded using oscilloscope.

The experiment was performed by applying a voltage of $80 \mathrm{kV}$ to $110 \mathrm{kV}$ with step $1 \mathrm{kV}$ and monitored using the oscilloscope. In every step, the thermography image as temperature data and leakage current were measured and stored in a database system.

The data was analyzed and discussed whether can be used as an indicator or not. And analyzed what is the correlation between leakage current and temperature.

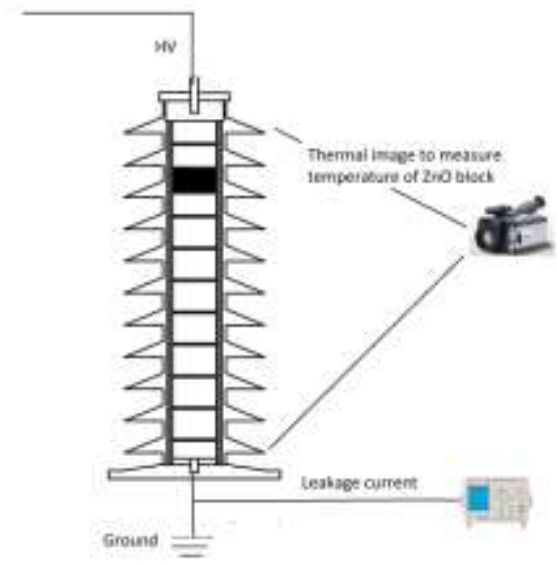

Figure 3. Experimental set up

The experiment was performed by applying a voltage of $80 \mathrm{kV}$ to $110 \mathrm{kV}$ with step $1 \mathrm{kV}$ and monitored using the oscilloscope. In every step, the thermography image as temperature data and leakage current were measured and stored in a database system.

The data was analyzed and discussed whether can be used as an indicator or not. And analyzed what is the correlation between leakage current and temperature.

\section{Results and Discussion}

The thermal image and leakage current of $132 \mathrm{kV} \mathrm{ZnO}$ surge arrester applied voltage $90 \mathrm{kV}$ were shown in Fig. $4 a$ and $4 b$ respectively.

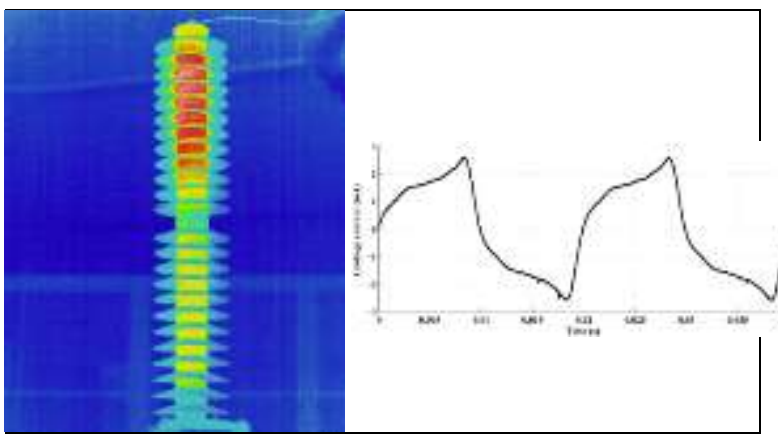

(a)

(b)

Figure 4. Thermal image (a) and leakage current (b) of $132 \mathrm{kV} \mathrm{ZnO}$ arrester (applied voltage $90 \mathrm{kV}$ ) 


\subsection{Temperature Profile of $\mathrm{ZnOArrester}$}

The temperature profile of $\mathrm{ZnO}$ surge arrester was examined for 8 hours. Fig. 5 shows the example of temperature profile of $\mathrm{ZnO}$ surge arrester when applied voltage $90 \mathrm{kV}$ as observed by a forward looking infrared camera. According to the theory, the amount of leakage current was generated by $\mathrm{ZnO}$ surge arrester.

In this example Fig. 5, the temperature hotspot of $\mathrm{ZnO}$ arrester was about $31.2^{\circ} \mathrm{C}$ and leakage current was about $240 \mu \mathrm{A}$. All thermal images were observed by its temperature profile and leakage current was used the maximum leakage current. The experiments were carried out at the initial resistive leakage current of $0.5,0.7$ and 1 $\mathrm{mA}$, respectively. When $\mathrm{AC}$ voltage corresponding to each initial leakage current was applied to the $\mathrm{ZnO}$ arrester block, the thermal profiles of $\mathrm{ZnO}$ arrester block were observed.

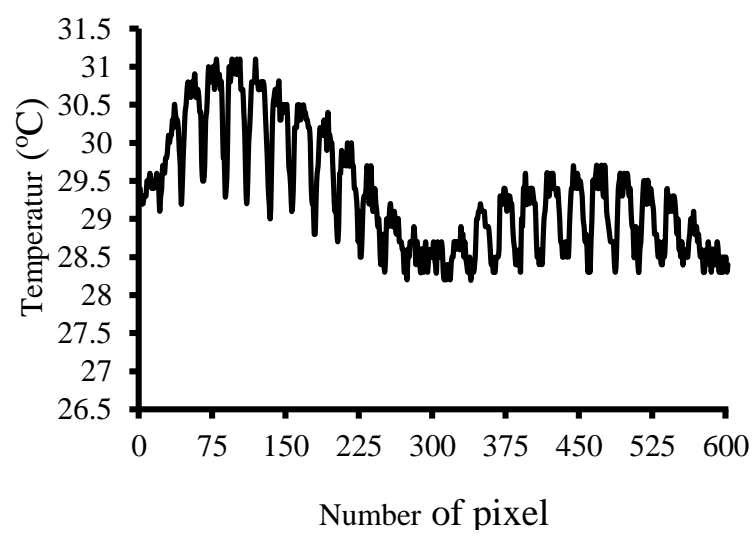

Figure 5. Thermal profile of $132 \mathrm{kV}$ ZnOarrester (applied voltage $90 \mathrm{kV}$ )

\subsection{Leakage Current}

When AC voltage was applied for 8 hours, showed leakage current flowing through $\mathrm{ZnO}$ surge arrester under normal conditions is used as one of the health monitoring techniques. However, the leakage current itself does not indicate the severity of degradation of $\mathrm{ZnO}$ element. So need temperature as contra indicator for monitoring condition arrester [2, 9, 10]. Hence, a sharp increase leakage current due to degradation or ageing of $\mathrm{ZnO}$ affect the temperature considerably. The higher leakage current may ultimately bring in the $\mathrm{ZnO}$ surge arrester to thermal instability and may result in complete failure or breakdown of the arrester.

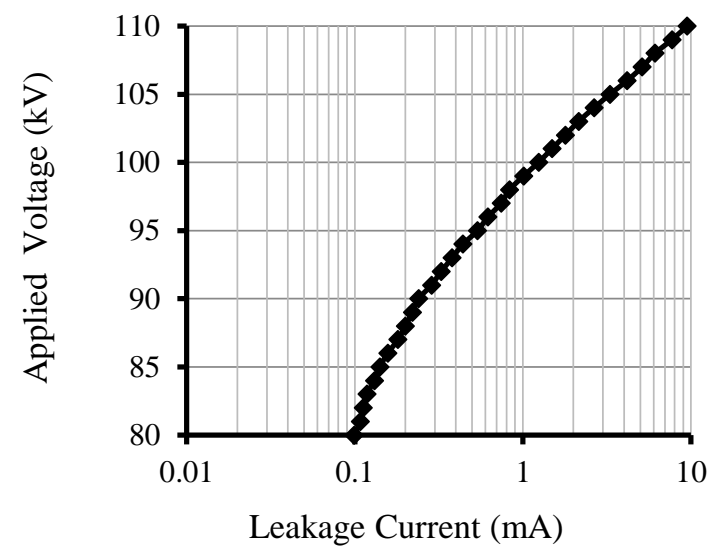

Figure 6. Leakage current of $\mathrm{ZnO}$ surge arrester for every applied voltage

Figure 6 shows the behaviors of the leakage current peaks as a function of the weekly measurements for the respective arresters samples.

\subsection{The Relationship between Leakage Current and Temperature}

Generally, the leakage currents which flowing through the $\mathrm{ZnO}$ arrester under power frequency $\mathrm{AC}$ voltage can be influenced the condition of $\mathrm{ZnO}$ arrester. The $\mathrm{ZnO}$ arrester is modeled as parallel resistor and capacitor. The resistive part of $\mathrm{ZnO}$ arrester generated the heat caused by leakage current.

At that time, the leakage current is slightly related to the temperature rise of the $\mathrm{ZnO}$ arrester especially inside block and is sensitive to the voltage distribution of the block. But the resistive leakage current generates joule heat, and thus molecule motion is promoted. The temperature rise occurs and finally, the life of the $\mathrm{ZnO}$ arrester block is shortened.

The temperature rise of $\mathrm{ZnO}$ arrester blocks results in the reduction of the internal resistance of the $\mathrm{ZnO}$ arrester block [7,8]. Table 1 shows the applied voltage from 80 to $110 \mathrm{kV}$ and the leakage current also temperature rise caused by leakage current.

Fig. 7 shows the temperature and leakage current versus applied voltage. As previously stated, the temperature rise of the $\mathrm{ZnO}$ arrester block brings about an increase in the resistive 
leakage current, and the increase of the current makes the temperature rise. In other words, the Joule's heat generation by the temperature rising changes the resistance of the $\mathrm{ZnO}$ arrester block.

Table 1. Applied voltage, leakage current and temperature

\begin{tabular}{|c|c|c|}
\hline $\begin{array}{c}\text { Applied } \\
\text { voltage }(\mathrm{kV})\end{array}$ & $\begin{array}{c}\text { Leakage } \\
\text { Current }(\mathrm{mA})\end{array}$ & Temperature $\left({ }^{\circ} \mathrm{C}\right)$ \\
\hline 80 & 0.099 & 29.62 \\
\hline 81 & 0.108 & 29.91 \\
\hline 82 & 0.1125 & 30.45 \\
\hline 83 & 0.118 & 30.63 \\
\hline$\ldots$. & $\ldots$. & $\ldots$. \\
\hline 107 & 5.1356 & 52.1 \\
\hline 108 & 6.11 & 53.5 \\
\hline 109 & 7.71 & 54.4 \\
\hline 110 & 9.51 & 55.2 \\
\hline
\end{tabular}

As indicated, the resistance of the $\mathrm{ZnO}$ arrester blocks with the initial leakage current of $1 \mathrm{~mA}$ is decreased gradually. So, in the condition of the initial leakage current of $0.099 \mathrm{~mA}$, the temperature of $\mathrm{ZnO}$ arrester is gradually increased with the lapse of time until the thermal runaway is occurred.

On the other hand, the resistance of $\mathrm{ZnO}$ arrester with the initial leakage current of 0.099 $\mathrm{mA}$ is slowly decreased with the lapse of time. Consequently, it can be concluded that the resistances of $\mathrm{ZnO}$ arrester increased according to the internal temperature change of the $\mathrm{ZnO}$ arrester.

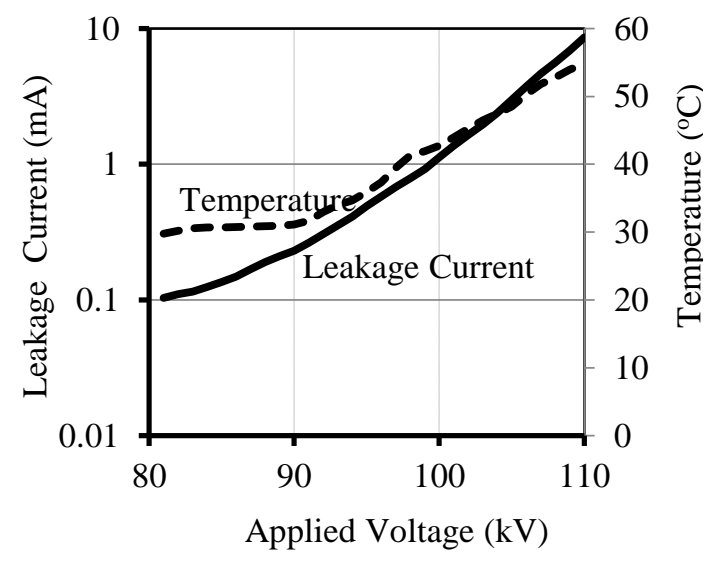

Figure 7. Relationship between leakage current and temperature

\section{Conclusion}

The degradation and thermal runaway phenomena of $\mathrm{ZnO}$ arrester block are closely related to the temperature limit of the $\mathrm{ZnO}$ arrester block. In the event that the temperature exceeds the acceptable limit $\mathrm{ZnO}$ block occurs thermal runaway, but below the temperature limit the $\mathrm{ZnO}$ arrester block maintains thermal equilibrium and stability. The linear relationship between temperature and leakage current of $\mathrm{ZnO}$ arrester can be used as indicator of aging or working condition identification of $\mathrm{ZnO}$ arrester. This phenomenon can occurs because the resistances of $\mathrm{ZnO}$ arrester vary with the change of internal temperature of the $\mathrm{ZnO}$ arrester

\section{Acknowledgments}

The authors would like to thank the Direktorat Pendidikan Tinggi, Kementerian Pendidikan Nasional, Research Grant, Electrical Department, Engineering Faculty, Andalas University for the financial and management support provided under contract No. 021/UN.16.05.D/PI/2017.

\section{References}

1. Novizon N., Z.A.M., Nouruddeen Bashir, N. Asilah, Thermal Image and Leakage Current Diagnostic as a Tool for Testing and Condition Monitoring of $\mathrm{ZnO}$ Surge Arrester. Jurnal Teknologi UTM, 2013. Vol.64(4).

2. Abdul-Malek, Z., Novizon, and Aulia. A new method to extract the resistive component of the metal oxide surge arrester leakage current. in Power and Energy Conference, 2008. PECon 2008. IEEE 2nd International. 2008.

3. Huijia, L. and H. Hanmei. Development of Tester of the Resistive Leakage Current of $M O A$. in Power and Energy Engineering Conference (APPEEC), 2010 Asia-Pacific. 2010.

4. Zhi-niu, X., et al., A Current Orthogonality Method to Extract Resistive Leakage Current of MOSA. Power Delivery, IEEE Transactions on, 2013. 28(1): p. 93-101.

5. Lira, G.R.S. and E.G. Costa, MOSA Monitoring Technique Based on Analysis of Total Leakage Current. Power Delivery, IEEE Transactions on, 2013. 28(2): p. 1057-1062.

6. Lee, S.-B., S.-J. Lee, and B.-H. Lee, Analysis of thermal and electrical properties of $\mathrm{ZnO}$ arrester block. Current Applied Physics, 2010. 10(1): p. 176-180. 
7. Abdul-Malek, Z., Novizon, and Aulia. Portable device to extract resistive component of the metal oxide surge arrester leakage current. in 2008 Australasian Universities Power Engineering Conference, AUPEC 2008, December 14, 2008 - December 17, 2008. 2008. Sydney, NSW, Australia: Inst. of Elec. and Elec. Eng. Computer Society.

8. Abdul-Malek, Z., et al. Field experience on surge arrester condition monitoring - modified shifted current method. in 2010 45th International Universities' Power Engineering
Conference, UPEC 2010, August 31, 2010 September 3, 2010. 2010. Cardiff, United kingdom: IEEE Computer Society.

9. Lundquist, J., et al., New method for measurement of the resistive leakage currents of metal-oxide surge arresters in service. Power Delivery, IEEE Transactions on, 1990. 5(4): p. 1811-1822.

10.Silva, D.A., et al. Polymer surge arresters:Degradation versus electrical performance. in Electrical Power and Energy Conference (EPEC), 2012 IEEE. 2012. 